\title{
Micromorphological analysis of Aranda Broga Blue orchid PLBs for Agrobacterium- mediated transformation system
}

\author{
Pavallekoodi Gnasekaran, Musfirah Nabilla Mustaffa, Jassim Uddain, and Sreeramanan Subramaniam* \\ School of Biological Sciences, Universiti Sains Malaysia, 11800 Gelugor, Penang, Malaysia. \\ Email: sreeramanan@usm.my
}

Received 4 February 2014; Received in revised form 24 March 2014; Accepted 9 April 2014

\begin{abstract}
Aims: The aim of this work was to analyse the morphological aspects of ABB's PLBs and interaction between ABB's PLBs and Agrobacterium.

Methodology and results: Aranda Broga Blue's (ABB) protocorm-like bodies (PLB) proliferated on Vacin and Went medium by incubating at $25 \pm 2{ }^{\circ} \mathrm{C}$ under $16 \mathrm{~h}$ semi-photoperiod was used to study the micromorphology of PLB, bacterial attachment and chemotaxis studies. The anatomy and micromorphology study indicates that ABB's PLBs provide the platform for attachment of Agrobacterium tumefaciens strain LBA 4404. Successful propagation of ABB's PLBs was achieved on modified Vacin and Went solid media supplemented with organic homogenates. Histological analysis of the development of ABB's PLBs shows it is a meristematic tissue and contains actively dividing cells. Transmission electron microscope (TEM) studies signify the presence of specialized organelles to indicate PLB is similar to a mature plant. Scanning electron microscope (SEM) observation on ABB's PLBs and bacterial attachment studies proves that trichomes and stomata on the surface facilitate the interaction with $A$. tumefaciens. Quantification of the attachment of Agrobacterium to ABB's PLBs using spectrophotometric system displayed higher affinity compared to the attachment mutant Escherichia coli DH5a. The interaction of Agrobacterium to ABB's PLBs was also evaluated based on chemotaxis studies. Highest motility respond of Agrobacterium was recorded (1.6 unit) towards severely wounded PLBs indicating wounding is necessary for the interaction between bacterium and PLB.
\end{abstract}

Conclusion, significance and impact study: Micromorphology of protocorm-like bodies (PLBs) enhances the physical interaction with bacteria proved that PLB is a suitable explant for the Agrobacterium-mediated genetic transformation.

Keywords: Arandaorchid, Agrobacterium tumefaciens, micromorphology, protocorm-like-bodies

\section{INTRODUCTION}

Malaysia is the most likely cradle of 'orchidhood' of the over 25,000 species found worldwide, and 850 were found in peninsular region (Shahril, 1999). The pulchritudinous of orchids lead to development of orchids industry upon high demands and viable commercialized market. Breeding orchids through conventional means is a lengthy process. Thus, it would have been beneficial if transgenic technologies could be applied for orchids to improve essential traits such as novel flower colour, delicate scent and shape, cut-flower longevity and many more. Aranda Broga Blue (ABB) is subjected to become one of the most important orchids grown for commercial production; therefore genetic engineering approaches are widely used to transfer potential genes into orchids (Liau et al., 2003; Sreeramanan et al., 2009). Currently, Agrobacterium-mediated transformation system has been productively and consistently used in orchids such as Cymbidium (Chen et al., 2002; Chin et al., 2007), Phalaenopsis (Belarmino and Mii, 2000; Mishiba et al., 2005; Sreeramanan et al., 2008), Dendrobium (Bunnag and Pilahome, 2012; Zheng et al., 2012), Cattleya (Zhang et al., 2010) and Oncidium (Liau et al., 2003). However, monocots including orchids are not the natural hosts of Agrobacterium strains, which made the initial trials difficult on the transformation of orchids with Agrobacteriummediated method. It is important to optimize the transformation system, because plants demonstrate wide variation in susceptibility to Agrobacterium (Tsay et al., 2012).

The accomplishment of genetic engineering in orchids depends on the totipotency of plant cells; for example the inherent ability of plant tissue to produce cells that can be regenerated into a completely viable plant (Teixeira da Silva et al., 2011). The success of orchid genetic transformation lies in the ability of putatively transformed tissue to regenerate. Protocorm-like bodies (PLBs) are the most commonly used target tissue for successful genetic transformation in orchids. Therefore Agrobacterium tumefaciens is a reliable genetic transformation tool in order to enhance the orchid features especially Aranda Broga Blue (ABB).

In this present study, we report that micromorphology of ABB's PLBs supports the attachment of $A$. tumefaciens to enhance transformation efficiency. $A$. tumefaciens- 
mediated transformation of $\mathrm{ABB}$ orchid is possible since A. tumefaciens chemically attracted towards exudates from ABB PLBs.

\section{MATERIALS AND METHODS}

\section{Plant materials}

In vitro culture of protocorm-like bodies (PLBs) of $\mathrm{ABB}$ was obtained from Plant Biotechnology Laboratory, 310, School of Biological Sciences, USM. The culture was incubated at $25 \pm 2{ }^{\circ} \mathrm{C}$ under $16 \mathrm{~h}$ semi-photoperiod under cool white fluorescent lamps (supplied by Philips TLD fluorescent light tubes of $36 \mathrm{~W}, 150 \mu \mathrm{mol} / \mathrm{m}^{2} . \mathrm{s}^{1}$. PLBs were proliferated on modified Vacin and Went medium supplemented with $15 \%$ coconut water, $20 \mathrm{~g} / \mathrm{L}$ banana and $20 \mathrm{~g} / \mathrm{L}$ potato extracts to produce large quantities of explants for experiments. PLBs were used as the explants for its anatomy, micromorphology, bacterial attachment and chemotaxis studies.

\section{Bacterial strain}

Agrobacterium tumefaciens (strain LBA4404 harbouring pCAMBIA 1304 plasmid containing $\beta$-glucuronidase (gusA) gene and antibiotic (nptll) resistance genes) was maintained at $-80{ }^{\circ} \mathrm{C}$ for long term storage in $70 \%(\mathrm{v} / \mathrm{v})$ glycerol.

\section{Histology analysis}

Ten (10) Protocorm-like bodies (PLBs) were fixed in formaldehyde (FAA) containing scintillation vial (2 PLBs in each vial) at room temperature for 1 week. The PLBs were then placed under running tap water for $24 \mathrm{~h}$. PLBs were then dehydrated by immersing in tertiary-butyl (TBA) alcohol of varying concentration. Then, PLBs were immersed in xylene until sample became transparent. This was followed by treatment with xylene and wax for 30 min to acclimatize PLBs to wax. Later, PLBs were treated with wax I, II, and III (Shandon HistoplastPelletised Paraffin Wax, Thermo Scientific) for 1 $\mathrm{h}$ respectively at $60^{\circ} \mathrm{C}$ in an oven (Memmert, Germany). PLBs were then placed in metal mold containing melted wax to form wax blocks. Wax blocks were then sliced using 6 Micron Microtome (Leica RM 2135) and placed on clean glass slides. Samples were then stained with safranin and fast green. Slides were observed using light microscope (Olympus BX41).

\section{Preparation of Agrobacterium tumefaciens culture}

Three (3) $\mathrm{mL}$ cultures from the glycerol stock were transferred into Luria-Bertani (LB) broth (Miller Hi Media, India) containing $50 \mathrm{mg} / \mathrm{L}$ kanamycin (Duchefa, Netherlands) and incubated at $28{ }^{\circ} \mathrm{C}$ and $120 \mathrm{rpm}$ overnight. Bacterial suspension were then streaked on solid LB medium containing $50 \mathrm{mg} / \mathrm{L}$ kanamycin using inoculation loop and incubated at $28{ }^{\circ} \mathrm{C}$ for $2-3$ days until a visible single colony forms. Single colony were then inoculated to LB broth containing $50 \mathrm{mg} / \mathrm{L}$ kanamycin and incubated at $28{ }^{\circ} \mathrm{C}$ and $120 \mathrm{rpm}$ for $16 \mathrm{~h}$ to reach an optimal density (OD) 0.9 units at OD $600 \mathrm{~nm}$. The OD of the $A$. tumefaciens suspension culture at $600 \mathrm{~nm}$ were adjusted to 0.9 using spectrophotometer (Hitachi U-1900 UV/VIS, Japan) before used for the bacterial attachment and chemotaxis studies. Escherichia coli strain DH5a harbouring pMRC 1301 plasmid consists of gus $A$ and nptll genes were prepared in the same manner as the $A$. tumefaciens and used as a control for attachment and chemotaxis studies.

\section{Microscopical studies of bacterial attachment}

Microscopical analysis was carried out to confirm the capability of $A$. tumefaciens strain LBA4404 harbouring pCAMBIA 1304 plasmid to adhere onto PLBs (Liau et al., 2003). Attachment mutant Escherichia coli strain DHa (pMRC 1301) was included as negative control in all the conducted experiments. Overnight grown bacterial cultures were pelleted (3400xg for $10 \mathrm{~min}$ ) and resuspended in $25 \mathrm{mM}$ phosphate buffer $(\mathrm{pH} 7.5)$ to infect PLBs. PLBs kept in $1.5 \mathrm{~mL}$ Eppendorf tubes were then co-cultivated with $250 \mu \mathrm{L}$ of bacterial suspension and incubated in a rotary shaker at $28^{\circ} \mathrm{C}$ at $25 \mathrm{rpm}$ for $2 \mathrm{~h}$. A total of 10 PLBs were immersed in bacterial suspension by placing 2 PLBs in each Eppendorf tubes. After $2 \mathrm{~h}$, unbound bacteria were removed by washing the PLB once with $1 \mathrm{~mL}$ fresh buffer and vortexed $30 \mathrm{sec}$ each time to discard unattached bacteria. Explants were then directly observed using optical microscopy or freeze dried for observation using scanning electron microscope (SEM) and transmission electron microscope (TEM) (Phillips CM12 with Docu Version 3.2 image analysis).

\section{Scanning Electron Microscope tissue preparation freeze drying technique}

Two (2) PLBs were placed on a planchette placed on filter paper lined Petri dish. The filter paper was damped with few drops of distilled water. The Petri dish was brought into fume hood and again damped with few drops of $2 \%$ osmium tetraoxide $\left(\mathrm{O}_{5} \mathrm{O}_{4}\right)$. The petri dish was closed immediately and kept in the fume hood for $2 \mathrm{~h}$. This is known as vapour fixation. Once the sample has been vapour fixed, the planchette was plunged into liquid nitrogen and transferred on to the peltier-cooled stage of the freeze dryer (Emitech k750, England) for about $10 \mathrm{~h}$. The planchette then kept in a dessicator if it's not to be viewed immediately. The specimen was then sputtered with $5-10 \mathrm{~nm}$ gold particles using SEM coating system (Polaron SC515, England) before viewing it under Leo Supra 50VP Field Emission SEM (Carl Zeiss SMT, Germany) equipped with Oxford INCA 400 energy dispersive microanalysis system.

\section{Transmission Electron Microscope tissue preparation}

Two (2) PLBs were fixed in McDowell-Trump fixative prepared in $0.1 \mathrm{M}$ phosphate buffer at $4{ }^{\circ} \mathrm{C}$ for $24 \mathrm{~h}$. The 
following day, the PLBs were washed in the $0.1 \mathrm{M}$ phosphate buffer for three times at $10 \mathrm{~min}$ interval. The PLB were then post fixed in $1 \%$ osmium tetraoxide prepared in the same buffer as above at room temperature for $2 \mathrm{~h}$. Then the PLBs were washed in distilled water for two times at 10 min interval. The PLBs were then dehydrated in a graded series of ethanol $(50 \%$ ethanol (15 $\mathrm{min}, 75 \%$ ethanol (15 $\mathrm{min}), 95 \%$ ethanol (15 min, twice), $100 \%$ ethanol (30 min, twice), and 100\% acetone (10 min, twice). Resin containing a mixture of acetone and Spurr's resin was prepared at a ratio of 1:1. The resin was infiltrated into the samples in a rotator for 15-30 min. The samples were infiltrated in Spur's mix overnight in the rotator. Samples were infiltrated in a new change of Spurr's mix for another $5 \mathrm{~h}$ in the rotator. Samples were embeded in resin beads formed in the mold. Samples were cured at $60{ }^{\circ} \mathrm{C}$ for 12 to 48 days. Samples were then sliced using ultramicrotome cutter and gathered on carbon planchette. Samples were stained with lead citrate and uranyl acetate and viewed under TEM.

\section{Quantification of bacterial attachment to PLBs}

Quantification of bacterial attachment assays were carried out according to method of (Pérez Hernández et al., $1999)$ in order to confirm the binding aptitude of $A$. tumefaciens strain LBA4404 harbouring pCAMBIA 1304 plasmid. Attachment mutant Escherichia coli strain DHa (pMRC 1301) was included as negative control in all the conducted experiments. Overnight grown bacteria suspension was centrifuged (Universal 320, Hettich Zentrifugen) at $3400 \mathrm{rpm}$ for $10 \mathrm{~min}$ at $4{ }^{\circ} \mathrm{C}$ for the quantification of Agrobacterium attachment onto PLBs. The bacterial pellet was suspended in $25 \mathrm{mM}$ phosphate buffer ( $\mathrm{pH} 7.5$ ). A total of 18 PLBs divided to 2 in each 1.5 $\mathrm{mL}$ Eppendorf tubes were maintained in $1 \mathrm{~mL}$ of $25 \mathrm{mM}$ phosphate buffer ( $\mathrm{pH}$ 7.5). For attachment, the Eppendorf tubes were loaded with $50 \mu \mathrm{L}$ aliquots of buffer suspended bacteria. Tubes were then incubated in a rotary shaker at $28{ }^{\circ} \mathrm{C}$ at $25 \mathrm{rpm}$ for $2 \mathrm{~h}$. After $2 \mathrm{~h}$, unbound bacteria were removed by washing the PLB once with $1 \mathrm{~mL}$ fresh buffer and vortexed $30 \mathrm{sec}$ each time to discard unattached bacteria. $\beta$-glucuronidase activity in the samples was measured following the preestablished method (Wilson et al., 1992). Washed explants were transferred to $1 \mathrm{~mL}$ of extraction buffer (50 $\mathrm{mM}$ sodium phosphate ( $\mathrm{pH} 7), 10 \mathrm{mM}$ dithiothreitol, $1 \mathrm{mM}$ sodium EDTA, $0.1 \%(\mathrm{v} / \mathrm{v})$ sodium lauryl sarcosine, $0.1 \%$ $(\mathrm{v} / \mathrm{v})$ triton $\mathrm{X}-100)$, vortexed and incubated at $37^{\circ} \mathrm{C}$ for 10 min. The GUS enzyme substrate $p$-nitrophenyl $\beta$-Dglucuronide was added at a final concentration of $1 \mathrm{mM}$. After incubation at $37{ }^{\circ} \mathrm{C}$ for $30 \mathrm{~min}$ reactions were stopped by the addition of $400 \mu \mathrm{L}$ of $400 \mathrm{mM} \mathrm{Na}_{2} \mathrm{CO}_{3}$ solution. GUS activity was quantified by measuring light absorbance at $415 \mathrm{~nm}$ in a spectrophotometer (Hitachi U1900 UV/VIS, Japan) $\left(\right.$ A $\left._{415 \mathrm{~nm}}\right)$ as described previously (Remans et al., 1999).

\section{Chemotaxis Assay}

Chemotaxis assays were carried out according to Shaw's protocol for the modified swarm agar plate method (Shaw, 1995). Three types of wounding were used in this assay such as Intact PLBs (positive control) (W1), PLBs subjected to mild wounding with sterile needles (W2) and PLBs subjected to severe wounding with scalpels (W3). Each set of experiment were repeated twice in triplicates. The data were analyzed using a one-way ANOVA and different between means were compared using Tukey test.

\section{RESULTS AND DISCUSSION}

\section{Micropropagation of Aranda}

Protocorm-like bodies (PLBs) are used as the target material for genetic transformation studies in orchids due to the rapid proliferation within short period of time and high capabilities to regenerate into complete plantlets (Sreeramanan et al., 2008). PLBs are somatic embryos that are meristematic in nature and can be induced to regenerate into whole plant. This is because PLB is a bipolar organ that develops shoot and root. Proliferation of PLBs could be established by providing sufficient nutrients required for growth (Vacin and Went, 1949). Therefore, modifications were made in the current study by including organic substances such as coconut water, potato homogenate and banana pulp.

Banana pulp was added to the modified Vacin and Went media because it contains higher level of iron, potassium, vitamin B6 and B12 and also trypthophan to promote PLBs growth. The stimulatory effect of banana pulp could be owed to its ability to stabilize the $\mathrm{pH}$ of the medium and the potent to act as antacid to neutralize acidity condition (Gnasekaraan et al., 2010). Higher percentage of sucrose, fructose and glucose concentrations in banana pulp extract makes it a better choice to be included in the proliferation media (Aktar et al., 2008). Banana has added benefit for ethylene production, which can induce germination and maturation. However, in large amount, it can also cause cell death. Ethylene reacts differently in plants.

Usually coconut water is added to tissue culture medium because it contains diphenyl urea, a growth factor which exhibits cytokinin-like responses (Gnasekaran et al., 2010). A balanced level of plant growth regulating hormones such as cytokinins and auxins in coconut water (Vyas et al., 2005) is expected to enhance the rapid growth of ABB's PLBs. Some compounds in the coconut water were reported to prevent the blackening of the plant tissues caused by the oxidation of phenolic compounds (Dix and Van Staden, 1982). After 2 weeks of subculture, PLBs grow rapidly; and absence of browning effect was noticed as well. 


\section{Histology of PLBs}

Histology is the study of the structure of plant or animal tissues using special staining techniques combined with observation under light microscopy. Histology was done to study the anatomy of ABB's PLB. The apical part of protocorm, consist of smaller cells, is the shoot apex while the basal part which functions as a 'storage organ', consist of larger parenchymatous cells (Figure 1A). Apical part of embryo is clearly shown in (Figure 1B).

Actively dividing cells were detected in ABB's PLBs. Figure $2 A$ shows the dividing nucleus which indicates the ongoing mitotic division beneath the epidermis for the continual growth of ABB's PLBs. Active cell division in the ABB's PLB compensate for the thickening of the somatic embryo. Histology studies also proved the presence of raphides (Figure 2B). Raphides are also known as crystal oxalate (Nakata, 2003) found abundantly in ABB's PLBs. Calcium oxalate crystal involves in calcium regulation, defense, and metal detoxification (Franceschi and Horner, 1980). In all cases, the crystals are formed from environmentally derived calcium and from biologically synthesized oxalate as part of calcium regulation (Nakata, 2003). Thus, it can be concluded that ABB's PLBs are either able to utilize the medium content to accumulate the calcium or it could be due to abundance of calcium that was not metabolized by the PLB itself, hence forming raphides. Calcium has long been recognized as one of the most important signalling components in plants (Trewavas and Knight, 1994; Bickerton and Pittman, 2012). Many abiotic and biotic stimuli are transduced into a cellular response by temporal and spatial changes in cellular calcium concentration. Therefore raphides will likely to be one of the reasons to signal the $A$. tumefaciens towards the PLBs, justifying the structure of raphide will be providing excellent plant-bacterium recognition. The crucial step of this interaction can be achieved. Vascular system starts differentiating basipetally in the center of the PLB during the development of shoot and root apex. Development of vascular bundles in ABB's PLBs was proven by the presence of coil shaped xylem (Figure 2C). Presence of xylem in ABB's PLBs ensures the efficient uptake of water. Anatomy of ABB's PLBs contribute understanding in fundamentals of establishment $A$. tumefaciens onto ABB's PLBs, the presence of actively dividing cells, raphides and xylem will be enhancing the interaction and attachment of $A$. tumefaciens on ABB's PLBs.

\section{SEM and TEM analysis of PLBs}

Scanning electron microscope (SEM) provides the information about the external morphology of the sample. Surface of PLBs are expected to have trichomes. Trichomes are single or multicellular outgrowths of the plant epidermis (Cherdantsev and Grigorieva, 2012) and collectively constitute the pubescence (hairness) of the plant surface (Nawab et al., 2011). These epidermal hairs are specialized for plant defence against herbivory by physical and chemical deterrents (Tian et al., 2012). Trichome was observed almost all over the surface of ABB's PLBs (Figure 3A). Multi branched trichomes which is hollow in nature was identified on the ABB's PLBs (Figure $3 \mathrm{~A}$ ). Trichome is a hollow structured projection (Redha et al., 2011), thus it may contain chemical attractant that attract the $A$. tumefaciens to attach to the ABB's PLBs. Furthermore, the morphology of trichomes facilitate in successful attachment. ABB's PLBs trichomes are branched which increase the surface area for bacterial attachment and results in efficient bacterial attachment.

Random distribution of stomata on the epidermis of PLB was identified through SEM studies. Figure 3B shows round shaped stomata possessing two guard cells. Stomata are microscopic pores on the surface (epidermis) of plants (Withers et al., 2011). Presence of stomata indicates that ABB's PLB undergoes respiration. Transpiration via stomata supplies water and minerals to the entire plant system (Withers et al., 2011). Stomata provide a natural opening on the surface of PLB for the access and attachment of the Agrobacterium cells (Underwood et al., 2007). It allows the in depth colonization by Agrobacterium cells into the plant cells. Stomata is the best place for $A$. tumefaciens to avoid being wash or food sanitization, it does not have active mechanism to prevent bacterial infection, thus provide the easiest place to be accessed by $A$. tumefaciens.

TEM analysis was determined to identify various organelles on the PLB cells. The observations indicate the presence of specialized organelles such as mitochondria (Figure 4A) and chloroplast (Figure 4B). Chloroplasts are specialized organelles found in all higher plant cells. Various shapes and sizes of mitochondria were observed in ABB's PLBs (Figure 4A). Mitochondria are membrane-bound organelles, forming folds called cristae as clearly seen in Figure 4A. The presence of specialized organelles such as mitochondria and chloroplast in ABB's PLB shows it's no different from an intact mature plant. Furthermore, it can be concluded that ABB's PLB will play self recovery role to prevent cell death in case of excessive colonization by $A$. tumefaciens since it's a photosynthesizing and respiring tissue.

Since ABB's PLB is a meristematic tissue and contains actively dividing cells it can also recover from the damages caused by colonization by Agrobacterium cells or wounds caused during handling process. Attributes such as the occurrence of specialized organelles, vascular system, actively dividing cells and ability to regulate calcium content prove ABB's PLB as the suitable explant for Agrobacterium-mediated transformation. Occurrence of trichomes and stomata on the surface of ABB's PLB further enhance Agrobacterium-mediated transformation by providing the area for successful attachment of Agrobacterium cells. Penetration and aggregation of bacteria via stomata and trichome has been recorded in previous years (Takeuchi and Frank, 2000; Burnett and Beuchat, 2001; Melotto et al., 2008). 


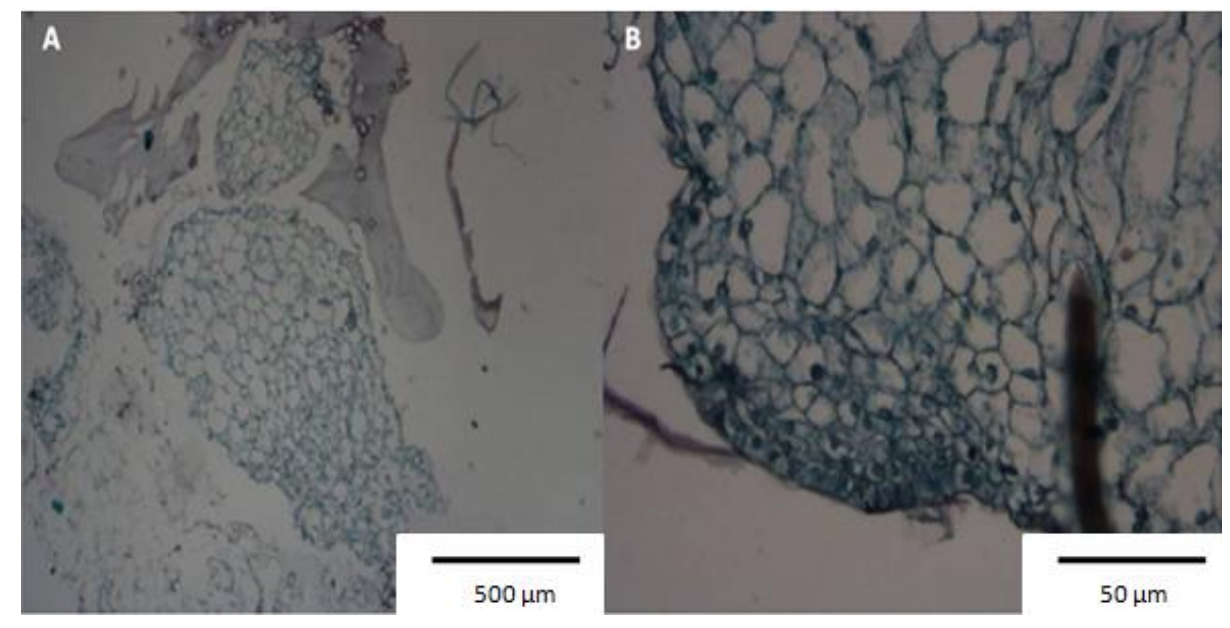

Figure 1: Well developed PLB contained (A) different sizes of cells, and (B) Apical part of PLB.

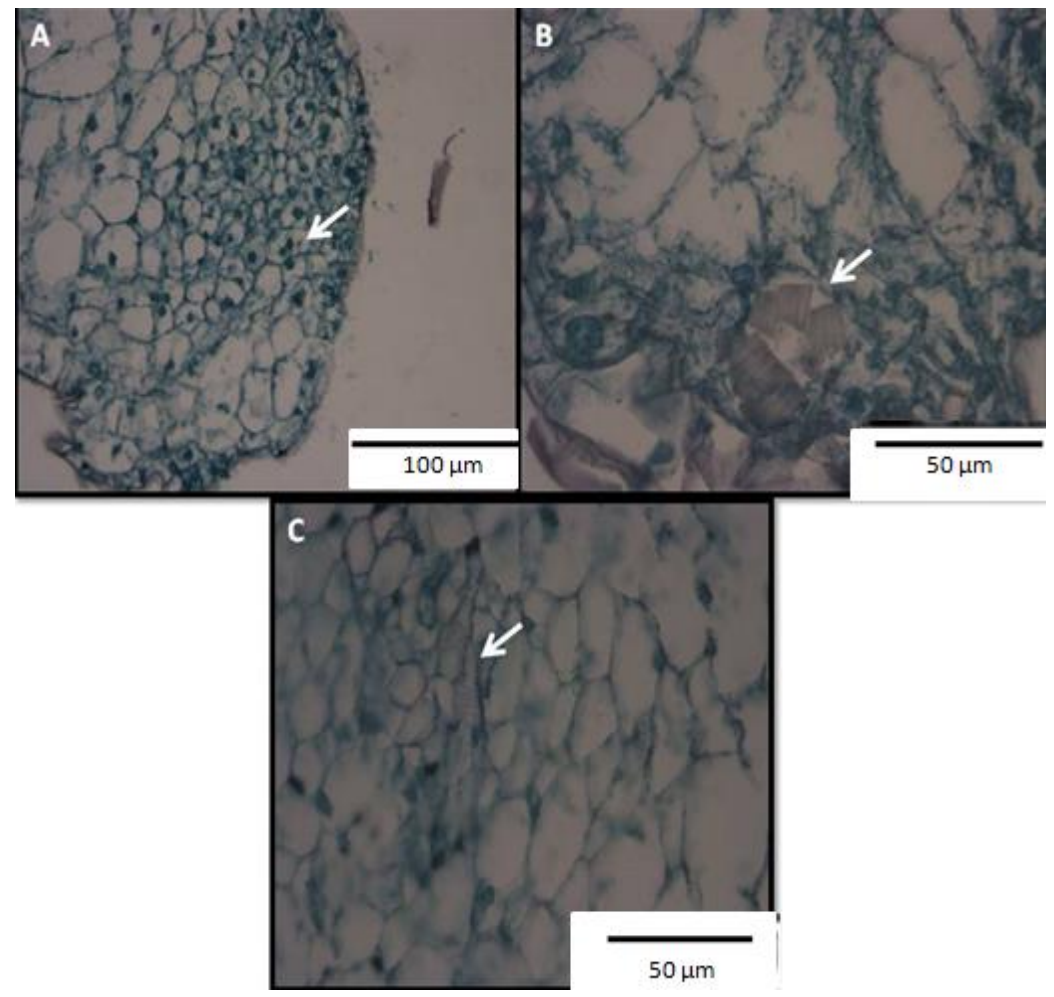

Figure 2:(A) Two nuclei cells suggest an event of active mitosis beneath the epidermis. Arrow indicate actively dividing cell;(B) Arrow indicates a stack of raphids;(C) Arrow indicates vascular bundle which is coil shaped xylem. 


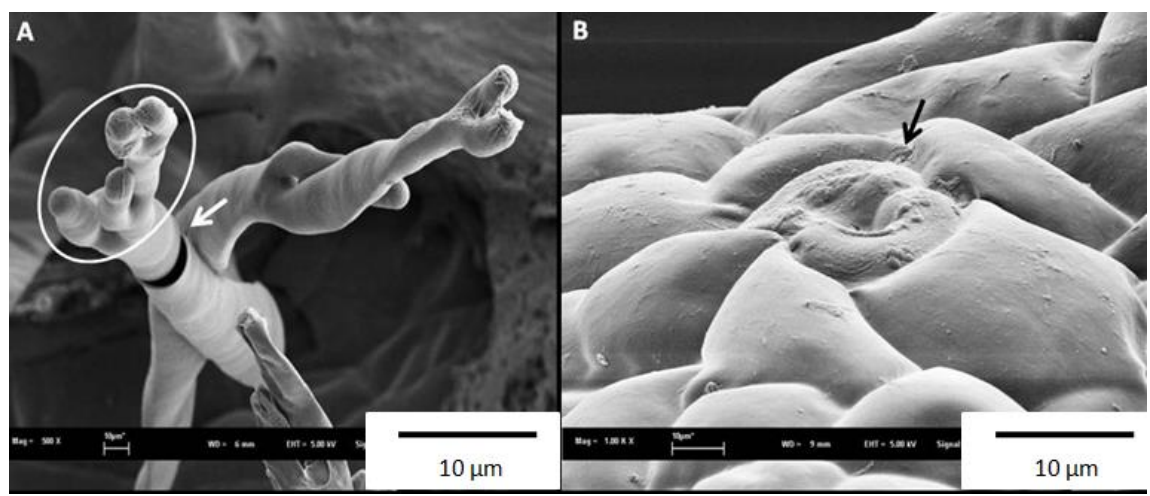

Figure 3: Elongated projections of a cluster of branched trichomes from the surface of the PLB. (A) Arrow indicates trichomes are hollow in cavity. Circle indicates the branched portion of PLB;(B) Arrow indicates the presence of stomata on the surface of PLB.
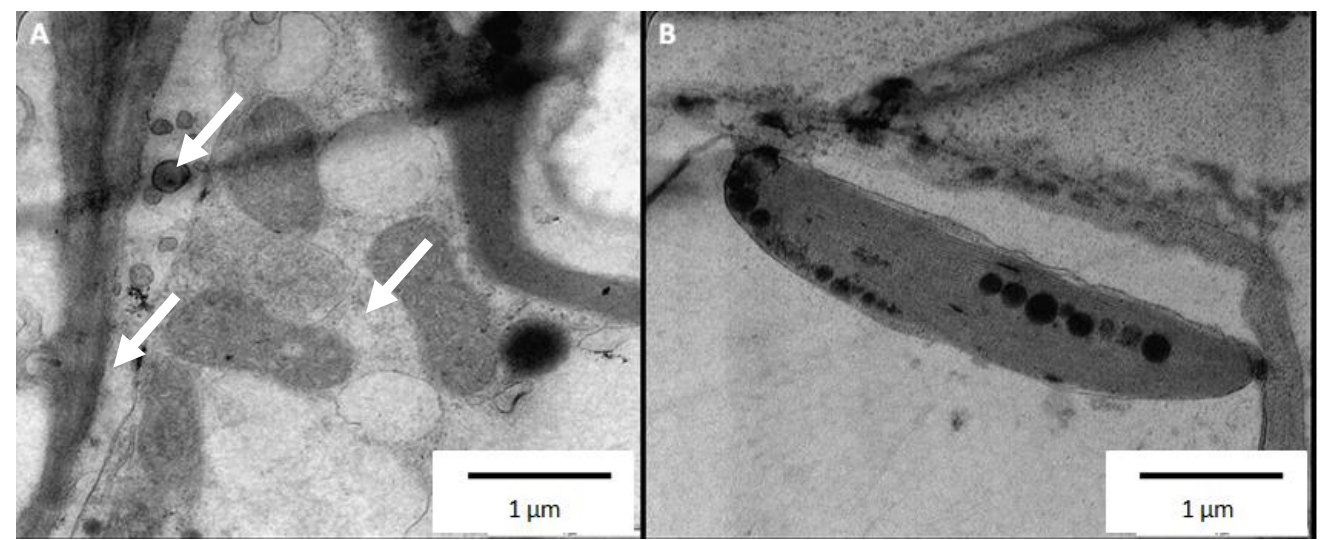

Figure 4:(A) Arrows indicate various shapes of mitochondria with highly folded cristae;(B) Chloroplast lines along the height of the cell wall.

\section{Quantification of Agrobacterium attachment on ABB's PLBs}

Bacterial attachment to PLB was quantified through spectrophotometric measurement $\left(A_{415}\right)$ of GUS expression in $A$. tumefaciens strain LBA 4404. Based on the results, the mean value of attachment of $A$. tumefaciencs was higher (83\%) compared to the negative control (Escherichia coli strain DH5a) (20\%) which is an attachment mutant (Figure 5). Therefore, the spectrophotometric GUS assay used for quantification of bacterial attachment shows the enhanced binding capacity for the attachment-efficient $A$. tumefaciens strain LBA 4404 over $E$. coli strain DH5a which is attachment mutant. Quantification is a study to measure the attachment of $A$. tumefaciens, by $83 \%$ attachment indicates a very positive result which means $A$. tumefaciens attached on ABB's PLBs due to facilitation of ABB's PLBs anatomies and $A$. tumefaciens behaviour as well. This shows that bacteria adhesion onto ABB's PLBs will aid the further studies of genetic modification event.

\section{Microscopical studies of bacterial attachment}

SEM observation shows a significant attachment of $A$. tumefaciens onto the surface of ABB's PLBs. The early step was the lateral (Figure 6A) or polar mode (Figure 6B) attachment of the single bacteria to the ABB's PLB surface in increasing number. This is followed by the initiation of formation of fibrils (Figure 6C) to anchor freely moving $A$. tumefaciens to the surface of PLB. Hence a larger number of $A$. tumefaciens will be indirectly bound to the PLB. Aggregates of bacteria could be seen to be held together by extensive networks of fibril (Figure 6D).

TEM analysis also proved the occurrence of $A$. tumefaciens along the cell wall of the cells (Figure 7). This indicates that $A$. tumefaciens have successfully penetrated and colonized internal area of the ABB PLB. There are many factors involved in successful attachment of bacteria on PLBs; such as bacterial density (Underwood et al., 2007), bacterial suspension at log phase and the structure of the plant tissue itself to make a suitable area for the attachment of the bacteria and wounding of explants (Wells and Butterfield, 1997; Dingman, 2000). For example, external structures such 
as trichome and stomata will enhance the attachment of A. tumefaciens onto the ABB's PLB.

Actively moving Agrobacterium cells around the trichomes were detected under the phase contrast microscopy; indicating colonization happens very fast and efficiently. The bacteria absorb certain wavelength that allows them to glow under phase contrast microscope. Hence, the glowing light (Figure 8A) proves the successful colonization of bacteria onto the PLBs. Phase contrast studies of trichome confirmed that this area was extensively colonized by bacteria whereby a cap-like formation was produced by massive aggregation of $A$. tumefaciens strain LBA 4404 on the tip of trichomes of ABB's PLBs (Figure 8B). As stated above, A. tumefaciens cells have successfully colonized the crevices at the opening of the stomata as well. The rough surface inside the opening of stomata provides a strong grip for Agrobacterium cells to make a strong contact. Same goes to wounding which produce phenolic exudates and also provide an open area for the bacteria to attach. Naturally $A$. tumefaciens infects plants through an open wound. It seeks for phenolic compounds which released from wound and chemotactically moves toward its source (Harighi, 2008; Bhattacharya et al., 2010). The T-DNA is then integrated into the plant's genome and directs the plant cell to synthesize opines (usually nopaline or agropine) which $A$. tumefaciens use as the energy source (Harighi, 2008). In Agrobacterium-mediated transformation studies, T-DNA is replaced by a novel gene expressing beneficial effect on the plant such as resistance to diseases, tolerance to environmental challenges or enhancing the aesthetic value.

\section{Chemotaxis Response of Agrobacterium tumefaciens LBA 4404}

Generally, wounded PLBs show higher bacterial chemotaxis response compared to the unwounded PLBs (Figure 9). After $24 \mathrm{~h}$, bacteria chemotaxis response was hasten towards severely wounded PLBs scoring a ratio of 1.6 unit (positive chemotaxis response since ratio is $\geq 1$ ) showing higher bacteria motility. This proves that $A$. tumefaciens LBA 4404 virulence characteristics to facilitate gene transfer for transformation purpose. Lower chemotaxis response of 1.3 and 1.0 unit (positive chemotaxis response since ratio is $\geq 1$ ) (Figure 9) was observed in mildly wounded and intact PLBs respectively. This shows that there is a significant different between the wounding level intended on the PLBs. The overall chemotactic response of $A$. tumefaciens LBA 4404 was positive to the ABB's PLBs although Agrobacterium was noticed to swarm backward away from the ABB's PLBs.

Chemotaxis assay is the study of affinity of $A$. tumefaciens towards plant exudates whether it moves toward or away from chemical attractant or repellent. The capability of bacteria to drive themselves through their surroundings, often in response to chemical and physical gradients, is a significant adaptive mechanism that promotes optimal positioning of cells at microscopic spatial scales. Commonly, motile bacteria move through fluids and along surfaces by using external appendages, including pili and flagella. The biofilm-forming plant pathogen Agrobacterium tumefaciens drives swimming motility by utilizing a small group of flagella localized to a single pole or the subpolar region of the cell (Merritt et al., 2007).

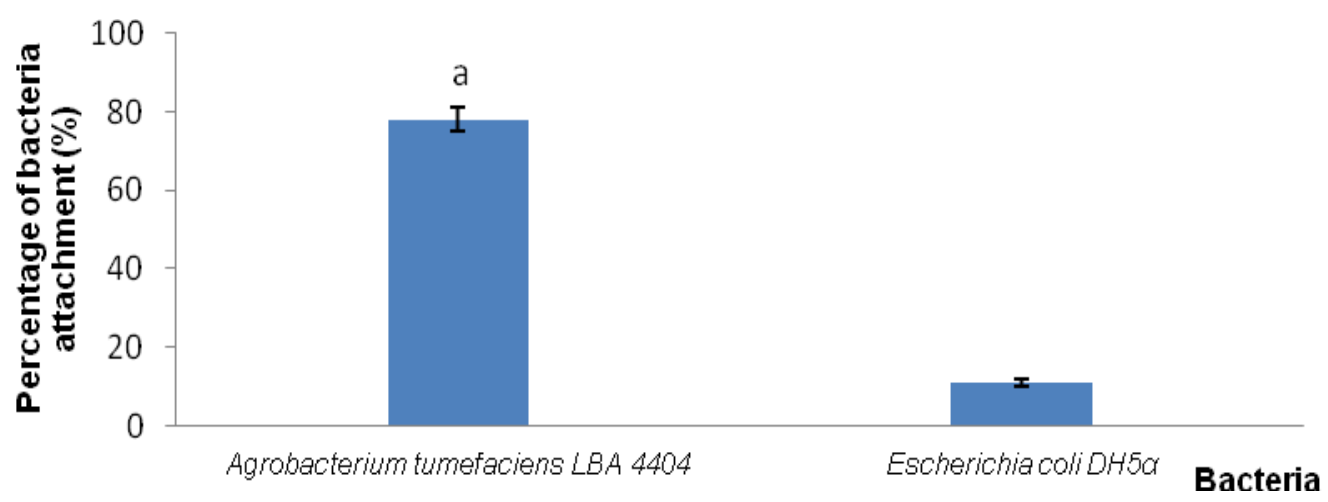

Figure 5: Quantification of Agrobacterium tumefaciens LBA 4404 and attachment mutant Escherichia coli strain DH5a onto ABB's PLBs. Data were analysed using one-way ANOVA and the differences contrasted using Tukey's multiple comparison test. Different letter represents significant difference at $0.05 \%$. 

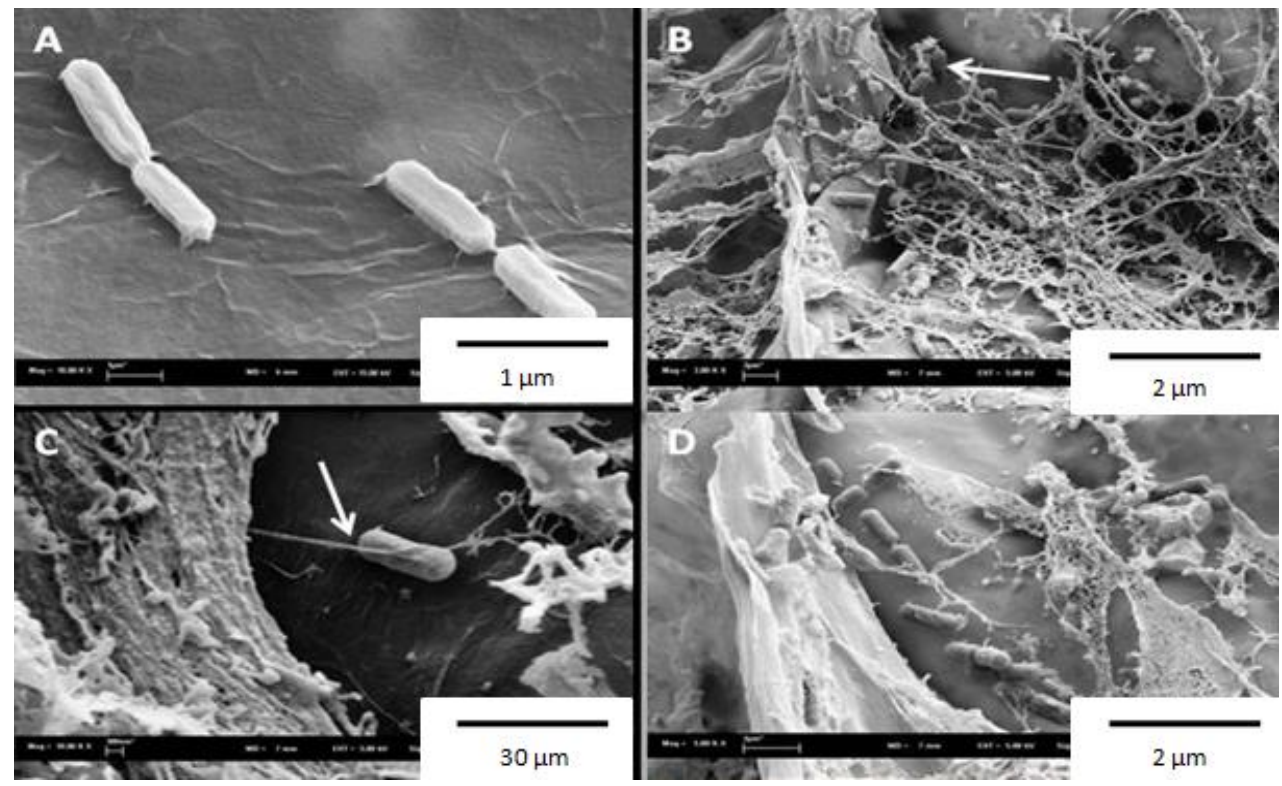

Figure 6: (A) Initial colonization of bacteria includes laterally bound bacteria;(B) Polarly bound bacteria. Arrow indicates Agrobacterium bound via polar mode attachment;(C) Initiation of formation of fibrillar net during the massive bacterial attachment;(D) Extensive massive network to form an Agrobacterial cluster.

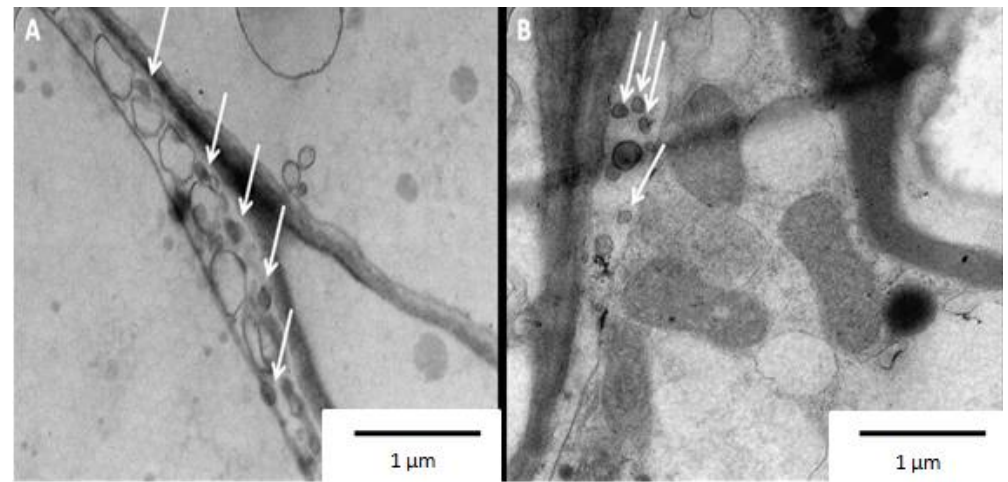

Figure 7: (A, B) A. tumefaciens strain LBA4404 successfully colonized the internal area of ABB PLB. Arrows indicate the round shaped structures which are actually $A$. tumefaciens found along the cell wall of the cells.
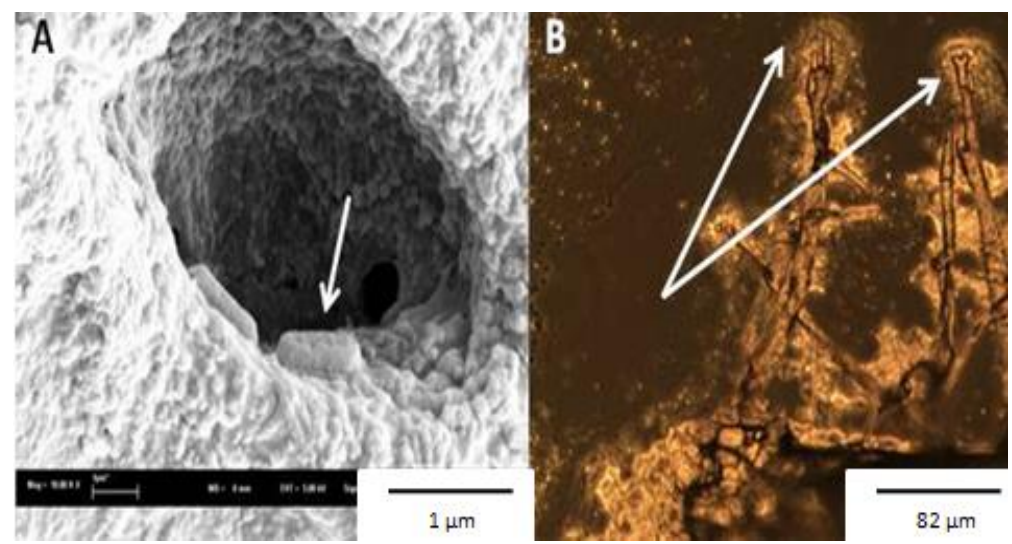

Figure 8: (A) Agrobacterium cells laterally bound to the inner surface of stomata;(B) Massive cap-like formation of Agrobacterium cells on the tip of trichome of the ABB PLB. 


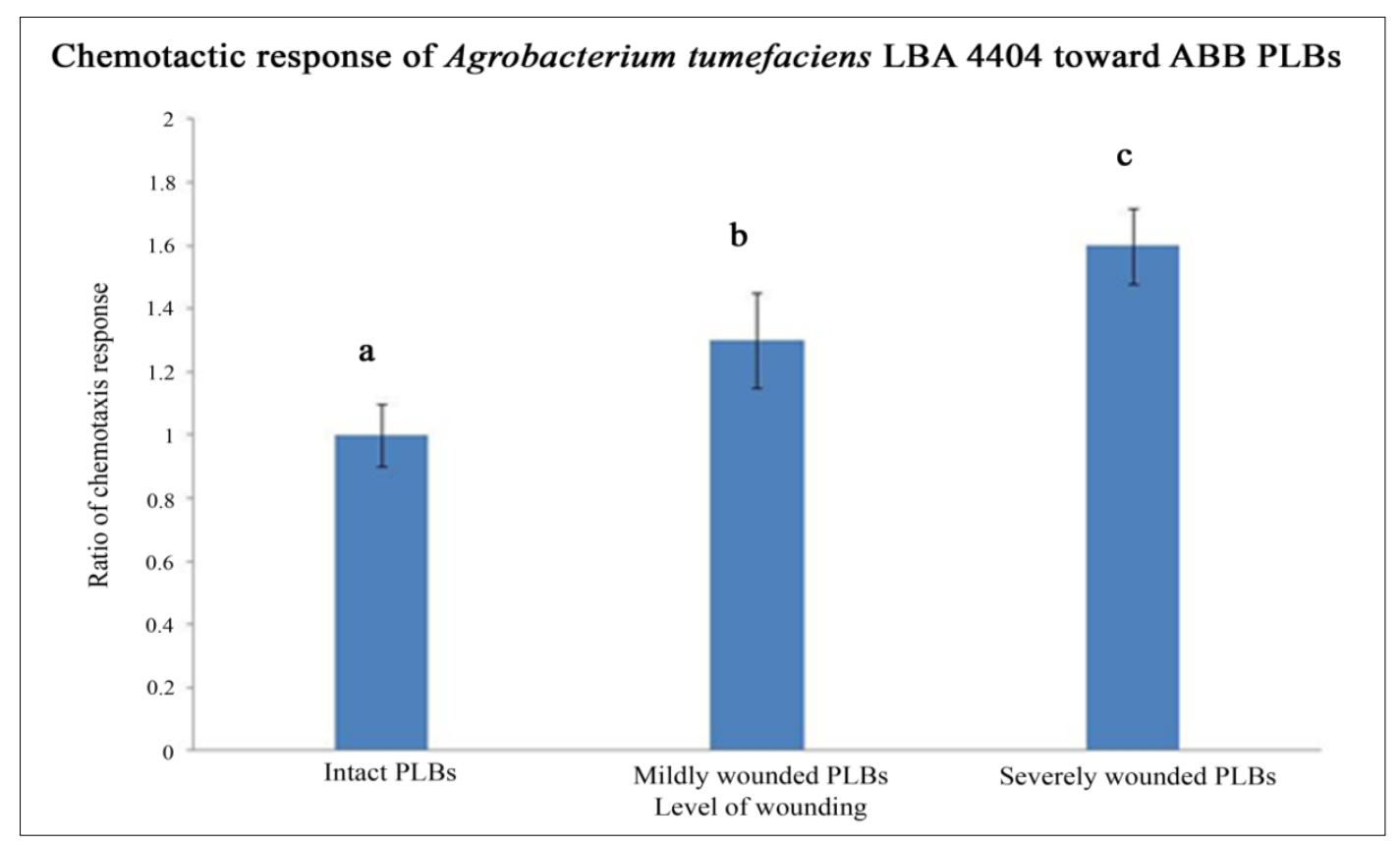

Figure 9: Chemotaxis of Agrobacterium tumefaciens LBA 4404 towards different levels of wounding on ABB's PLBs after $24 \mathrm{~h}$. Data were analysed using one-way ANOVA and the differences contrasted using Tukey's multiple comparison test. Different letter represents significant difference at $0.05 \%$.

\section{CONCLUSION}

Histology and microscopy recognizes the structures of protocorm-like bodies (PLBs), meanwhile the SEM and TEM are important aspect of this study in order to view the $\mathrm{ABB}$ and interaction with $A$. tumefaciens. GUS expression indicates successful attachment and viewed under phase contrast microscope. Quantification of attachment and chemotaxis assay are established according to the standard protocols, supplying enough information on the interaction of $A$. tumefaciens and the host.

\section{ACKNOWLEDGEMENT}

This work was supported by Universiti Sains Malaysia Research University Research Grant Scheme (USM-RU 2011).

\section{REFERENCES}

Aktar, S., Nasiruddin, K. M. and Hossain, K. (2008). Effects of different media and organic additives interaction on in vitro regeneration of Dendrobium orchid. Journal of Agriculture and Rural Development in the Tropics 6, 69-74.

Belarmino, M. M. and Mill, M. (2000). Agrobacteriummediated genetic transformation of a Phalaenopsis orchid. Plant Cell Reports 19, 435-442.
Bhattacharya, A., Sood, P. and Citovsky, V. (2010). The roles of plant phenolics in defence and communication during Agrobacterium and Rhizobium infection. Molecular Plant Pathology 11, 705-719.

Bickerton, P. D. and Pittman, J. K. (2012). Calcium signalling in plants. John Wiley online library.

Bunnag, S. and Pilahome, W. (2012). Agrobacteriummediated transformation of Dendrobium chrysotoxum Lindl. African Journal of Biotechnology 11(10), 24722476.

Burnett, S. L. and Beuchat, L. R. (2001). Human pathogens associated with raw produce and unpasteurized juices, and difficulties in decontamination. Journal of Industrial Microbiology and Biotechnology 27, 104-110.

Chen, L., Hatano, T. and Niimi, Y. (2002). High efficiency of Agrobacterium-mediated rhizome transformation in Cymbidium. Lindleyana 17, 130-134.

Cherdantsev, V. G. and Grigorieva, O. V. (2012). Morphogenesis of active shells. Biosystems 109(3), 314-328.

Chin, D. P., Mishiba, K. and Mii, M. (2007). Agrobacterium-mediated transformation of protocormlike bodies in Cymbidium. Plant Cell Reporter 26, 735-743.

Dingman, D.W. (2000). Growth of Escherichia coli O157:H7 in bruised apple (Malusdomestica) tissue as influenced by cultivar, date of harvest, and source. 
Applied and Environmental Microbiology 66, 1077 1083.

Dix, L. and Van Staden, J. (1982). Auxin and gibberelinelike substances in coconut milk and malt extract. Journal of Plant Biotechnology 1(1), 239-246.

Franceschi, V. R. and Horner, Jr. H. T. (1980). Calcium oxalate crystals in plants. Botanical Review 46, 361427.

Gnasekaran, P., Xavier, R., Uma Rani, S. and Sreeramanan, S. (2010). A study on the use of organic additives on the protocorm-like bodies (PLBs) growth of Phalaenopsisviolacea orchid. Journal of Phytology 2(1), 029-033.

Harighi, B. (2008). Role of CheY1 and CheY2 in the chemotaxis of $A$. tumefaciens toward acetosyringone. Current Microbiology 56(6), 547-552.

Liau, C. H., You, S. J., Prasad, V., Hsiao, H. H., Lu, J. C., Yang, N. S. and Chan, M. T. (2003). Agrobacterium tumefaciens-mediated transformation of an Oncidium orchid. Plant Cell Reports 21(10), 993-998.

Melotto, M., Underwood, W. and He, S. Y. (2008). Role of stomata in plant innate immunity and foliar bacterial diseases. Annual Review of Phytopathology 46, 101-122.

Merritt, P. M., Danhorn, T. and Fuqua, C. (2007). Motility and chemotaxis in Agrobacterium tumefaciens surface attachment and biofilm formation. Journal of Bacteriology 189(22), 8005-8014.

Mishiba, K. I., Chin, D. P. and Mii, M. (2005). Agrobacterium-mediated transformation of Phalaenopsisby targeting protocorms at an early stage after germination. Plant Cell Reporter 24, 297303.

Nakata, P. A. (2003). Advances in our understanding of calcium oxalate crystal formation and function in plants. Plant Science 164(6), 901-909.

Nawab, N. N., Khan, I. A., Khan, A. A. and Amjad, M. (2011). Characterization and inheritance of cotton leaf pubescence. Pakistan Journal of Botany 43(1), 649658.

Pérez Hernández, J. B., Remy, S., Galán Saúco, V., Swennen, R. and Sági, L. (1999). Chemotactic movement and attachment of Agrobacterium tumefaciens to banana cells and tissues. Journal of Plant Physiology 155(2), 245-250.

Redha, A., Al-Mansour, N., Suleman, P., Afzal, M., AlHasan, R. (2011). Leaf traits and histochemistry of trichomes of conocarpus lancifoliusa combretaceae in semi-arid conditions. American Journal of Plant Sciences2, 165-174.

Remans, T., Schenk, P. M., Manners, J. M., Grof, C. P. L. and Elliot, A. R. (1999). A protocol for the fluorometric quantification of mGFP5-ER and sGFP (S65T) in transgenic plants. Plant Molecular Biology Reporter 17, 385-395.

Shahril, K. Z. (1999). Highland orchids of peninsular Malaysia. WWF Malaysia Publication, Petaling Jaya, Malaysia pp. 1-8.
Shaw, C. H. (1995). New insights on T-DNA transfer. Trends in Microbiology 1(9), 325-327.

Sreeramanan, S., Vinod, B., Poobathy, R. and Rathinam, X. (2009). Chemotaxis movement and attachment of Agrobacterium tumefaciens to Phalaenopsis violacea orchid tissues: An assessment of early factors influencing the efficiency of gene transfer. Tropical Life Sciences Research 20(1), 3949.

Sreeramanan, S., Vinod, B., Sashi, S. and Xavier, R. (2008). Optimization of the transient Gus a gene transfer of Phalaenopsis violacea orchid via Agrobacterium tumefaciens: An assessment of factors influencing the efficiency of gene transfer mechanisms. Advances in Natural and Applied Sciences 2, 77-88.

Takeuchi, K. and Frank, J. F. (2000). Penetration of Escherichia coli 0157: $\mathrm{H} 7$ into lettuce tissues as affected by inoculum size and temperature and the effect of chlorine treatment on cell viability. Journal of Food Protection 63(4), 434-440.

Teixeira da Silva, J. A., Chin, D. P., Van, P. T. and Mii, M. (2011). Transgenic orchids. Scientia Horticulturae 130(4), 673-680.

Tian, D., Tooker, J., Peiffer, M., Chung, S. H. and Felton, G. W. (2012). Role of trichomes in defense against herbivores: Comparison of herbivore response to woolly and hairless trichome mutants in tomato (Solanum lycopersicum). Planta (4), 10531066.

Trewavas, A. and Knight, M. (1994). Mechanical signalling, calcium and plant form. Plant Molecular Biology 26(5), 1329-1341.

Tsay, H. S., Ho, H. M., Gupta, S. K., Wang, C. S., Chen, P. T. and Chen, E. C. F. (2012). Development of pollen mediated activation tagging system for Phalaenopsis and Doritaenopsis. Electronic Journal of Biotechnology 15(4). http://dx.doi.org/10.2225/vol15-issue4-fulltext-1.

Underwood, W., Melotto, M. and Yang He, S. (2007). Role of plant stomata in bacterial invasion.Cell Microbiology 9, 1621-1629.

Vacin, E. F. and Went, F. W. (1949). Some pH changes in nutrient solutions. Botanical Gazette 110, 605-613.

Vyas, S. J. N., Tak, K. and Purohit, S. D. (2005). In vitro adventitious shoot bud differentiation and plantlet regeneration in Feronialimonia L. (Swingle). In Vitro Cellular and Developmental Biology-Plant 41, 296309.

Wells, J. M. and Butterfield, J. E. (1997).Salmonella contamination associated with bacterial soft rot of fresh fruits and vegetables in the marketplace. Plant 81, 867-872.

Wilson, K. J., Hughes, S. G. and Jefferson, R. A. (1992). The Escherichia coligus operon: Induction and expression of the gus operon in E. coli and the occurrence and use of GUS in other bacteria. In: GUS Protocols: Using the GUS Gene as a Reporter of Gene Expression. Gallagher, S. R. (Ed.). Academy Press Inc, San Diego. pp. 7-23. 
Withers, C. M., Gay, A. P. and Mur, L. A. J. (2011). Are stomatal responses the key to understanding the cost of fungal disease resistance in plants? Journal of the Science of Food and Agriculture 91, 1538-1540.

Zhang, L., Chin, D. P., Fukami, M., Ichikawa, H., Nakamura, I. and Mii, M. (2010).Agrobacteriummediated genetic transformation of Cattleyawith an Odontoglossumringspot virusreplicase gene sequence. Plant Biotechnology 27, 421-426.

Zheng, Q., Zheng, Y. P., Wang, G. D., Guo, W. M., Fan, W. F. and Wang, C. (2012). Sonication-assisted Agrobacterium-mediated transformation of the ACC gene to interfere the production of ethylene in Spring Dendrobium cv. 'Sanya'.Russian Journal of Plant Physiology 59(2), 266-274. 